linkage groups. As the number of antigens, enzymes and other genetic markers that can be readily assayed increases, the technique is bound to become more popular, and other linkage groups will soon be recognized. After that the problem will be to refine methods for the analysis of linkage within a particular chromosome. For example, it may be possible to do this by analysing the phenotypes of cells containing chromosomes which have suffered deletion mutations of varying severity. As for medical exploitations, a dictionary of human linkage groups could immediately prove useful, in foetal medicine, for the early detection of genetic metabolic defects, or for the antigenic preselection of sperm before fertilization.

\section{Chip Off the Old Block}

No international committee likes to die a natural death, so the phoenix-like emergence of an International Geodynamics Commission to take over the running when the Upper Mantle Project comes to an end is hardly a surprise. By all accounts Professor Coulomb of Paris, who is bowing out of geopolitics after distinguished service, was concerned that a strong body should continue to exist, and an ad hoc committee has been at work in the past year trying to pinpoint the growth areas which needed emphasizing. As a result of this, a report was issued last July recommending a strong interdisciplinary approach to the problems of earth sciences in the $70 \mathrm{~s}$. The emphasis of this report is very firmly on the new tectonics approach and on the significance of lateral heterogeneity in all properties of the Earth in the outer 700 $\mathrm{km}$. It is satisfactory that the report was constructed by relatively young earth scientists who have contributed much to our present understanding of the Earth, and the international example of letting the youngsters decide the programme is one that many national committees would do well to emulate.

The Commission has recently had its first meeting to produce an agreed statement and four needs were emphasized in these meetings.

(1) An increased understanding of the forces and processes between lithospheric blocks or plates.

(2) Studies aimed at understanding the driving forces on these blocks, involving inter alia laboratory studies at high pressures and temperatures.

(3) Some new ideas on the as yet little understood vertical movements within blocks.

(4) Palaeogeophysical studies to determine whether present day processes were equally valid in past geological time.

Partly from an obvious desire to relate global geophysics to human needs, the Commission appears to have placed hope in economic advantages from deep drilling programmes comparable with the present JOIDES project. A recent discovery of copper in a JOIDES hole may help their case.

The Commission's deliberations are notable both for what was included and what was omitted. The very strong emphasis on a block or plate approach to the earth sciences is most important. Some people who should know better seem woefully ignorant of the enormous implications of the revolution of the last three years. The Commission has clearly laid down its belief in these new approaches and also in problem orientation rather than science for science's sake. Equally it has been careful to avoid giving any pats on the back to specific projects which might lead to its being used as a lever to extort financial support. Notably absent is any great enthusiasm for planetary exploitation, for local studies of "unusual regions" and for geotraverses (whether seismic, magnetic or gravity) -vastly expensive and largely useless operations that some countries have in the past committed themselves to.

So there is no recipe to national committees on what to support and what not to support, but a fairly clear indication of the direction in which the experts feel things should go. What exactly the Commission will succeed in doing remains to be seen. It has little power except persuasion and it is undoubtedly going to alienate many by being so forward-looking. The earth sciences are moving so fast that there are bound to be many who fall by the wayside, but on the other hand the quality of new recruits to the subject is encouraging. At first sight the Commission seems to be defining goals which are accessible to very few, but undoubtedly it will try to encourage all workers in the field to see national capabilities in a global programme. Whether Britain acts to implement financially work which is in accord with the aims of the Commission remains to be seen. Its record of official support for the Upper Mantle Project was not very inspiring despite the fine reports which were pericdically distributed showing everyone apparently working on the Upper Mantle. There is clearly no reason why Britain should force earth scientists to follow the precepts of the Commission. On the other hand one hopes that there will be at least an awareness of the need to give extra help to those who take its recommendations seriously.

\section{POLYNUCLEOTIDES \\ Looking at Coils}

\section{from our Molecular Biology Correspondent}

IT is clearly possible to leap into the deep end of molecular biology and survive, with no more knowledge about the physical properties of nucleic acids than what pairs with what. But to uncover the rules that govern the structures and interactions of nucleic acids it is necessary to study the properties of the ordered 